\title{
Electricity Demand and Supply Planning Analysis for Sumatera Interconnection System using Integrated Resources Planning Approach
}

\author{
Suhono $^{1}$, Sarjiya $^{2}$, Sasongko Pramono Hadi $^{3}$ \\ ${ }^{1}$ Department of Electrical Engineering and Informatics, Vocational College, Universitas Gadjah Mada, Indonesia. \\ ${ }^{2,3}$ Department of Electrical Engineering and Information Technology, Faculty of Engineering, Universitas Gadjah Mada, Indonesia
}

\begin{tabular}{l} 
ARTICLE INFO \\
\hline Article histories: \\
Received May 21, 2019 \\
Revised July 4, 2019 \\
Accepted July 10, 2019 \\
\hline Keywords: \\
Energy planning \\
Sumatra electricity \\
Integrated resource planning \\
LEAP \\
Optimization
\end{tabular}

\begin{abstract}
The Sumatra interconnection system, which is the second-largest electricity system in Indonesia, is often experiencing rolling blackouts. That caused by a lack of supply from the power generating system of Sumatra. The Government has planned to develop new power plants through the fast track program (FTP). Until 2015, either power outages and supply shortages are still common. Therefore, an analysis of long-term electricity planning needed to support energy security in Sumatra. The Sumatra electricity system was modelled using integrated resource planning as a framework and the long-range energy alternative planning (LEAP) software as a tool to build and simulate the model. Three groups of scenarios will be compared are the fast track program (FTP) scenario, the biofuel mandatory (BM) scenario and optimization (OPT) scenario. The results show that the implementation of DSM programs through energy conservation scenario would be able to reduce the electricity demand in the future. On the other side, the alternative scenario shows that the electricity deficit could be resolved in 2022, while the optimization scenario shows that energy diversity would resolve the electricity crisis in the Sumatra interconnection system.
\end{abstract}

Copyright $@$ 2019. Published by Universitas Ahmad Dahlan. All rights reserved

\section{Corresponding author:}

Suhono,

Department of Electrical Engineering and Informatics,

Vocational College, Universitas Gadjah Mada,

Sekip Unit III, Catur Tunggal, Depok, Sleman, Yogyakarta 55281, Indonesia

Email: akhisuhono@ugm.ac.id

\section{INTRODUCTION}

The Sumatra interconnection system, which is the second-largest electricity system in Indonesia, is often experiencing rolling blackouts [1]. That caused by a lack of supply from the power generating system of Sumatra. The Government has planned to develop new power plants trough the fast track program (FTP). The Sumatra power generating system was included in the program.

In the process of generation of electricity, the Government of Indonesia is committed to reducing greenhouse gas emissions resulting from these processes. That is demonstrated by the publication of the National Action Plan for Greenhouse Gas reduction (RAN-GRK). According to the RAN-GRK, the government seeks to lower emissions by $26 \%$ to $41 \%$. The use of renewable energy and clean technology utilization for electricity generation is also considered one of them based on a policy that is also known as biofuel mandatory. The power sector in Indonesia is targeted using biodiesel as much as $30 \%$ and pure plant oils (PPO) as much as $20 \%$ of the total capacity requirements by 2025 [2].

Two main aspects are expected to solve the power shortage in Sumatera. They are the government's policy and the potential energy resource in Sumatera. However, the electricity crisis still occurs in Sumatera system. Based on this situation, an analysis of long-term electricity planning is needed to figure the impact of those government policies. 
Analysis of energy system generally needs an energy model [3],[4]. The traditional electricity planning model was used to focus on the supply-side. On the other side, the demand-side have less attention. This condition triggers the emergence of ideas for developing a model with the flexibility of integrating both supplyside and demand-side. The model is known as integrated resource planning (IRP). IRP can be implemented to analyze the impact of supply-side management, demand-side management or a combination of those. Other advantages of using IRP are cost and environmental included. A tool which can be used to develop the IRP model is long-range energy alternative planning (LEAP).

The main objective of this research is to analyze the impact of the implementation of government policies through the FTP program (phase 1 and phase 2) and biofuel mandatory against electric energy demand compliance of the Sumatra system, then analyzing the best options of integration policies on the demand side and the supply side.

\section{Sumatra electricity system}

The Indonesian electricity is dominated by the JAMALI (Java-Madura-Bali) system. Almost 50\% of the electricity demand is located in JAMALI. However, its sales growth was lower than the others. PT PLN records the Sumatra system was the highest sales growth before 2012 while the Eastern Indonesia system was the highest sales growth by 2013. Electricity sales growth in Indonesia is presented in Table 1. According to data in Table 1, the electricity sales in Sumatra system was quite high. However, based on the electrification ratio data in Table 2, the electricity produced by the Sumatra power system has not been able to reach the entire community. The electrification ratio was $69.4 \%$ in 2011 . It raised to $77.4 \%$ in 2012.

Table 1. Electricity sales growth in Indonesia (PT PLN Persero)

\begin{tabular}{lccccc}
\hline \multicolumn{1}{c}{ Region } & $\mathbf{2 0 0 9}$ & $\mathbf{2 0 1 0}$ & $\mathbf{2 0 1 1}$ & $\mathbf{2 0 1 2}$ & $\mathbf{2 0 1 3}$ \\
\hline Indonesia & 9,42 & 10,66 & 7,3 & 10,2 & 8,6 \\
Jawa - Bali & 3,31 & 8,92 & 6,5 & 9,3 & 8,2 \\
Sumatera & 7,22 & 11,63 & 9,3 & 12,6 & 8,0 \\
Kalimantan & 9,56 & 10,32 & 10,1 & 12,9 & 7,8 \\
Sulawesi & 8,77 & 10,68 & 11,0 & 13,7 & 14,4 \\
Eastern Indonesia & 9,91 & 10,70 & 13,0 & 16,1 & 13,9 \\
\hline
\end{tabular}

*Data realization until September 2013 compared to January-September 2012

Tabel 2. Electrification ratio in Indonesia (PT PLN Persero)

\begin{tabular}{lcccc}
\hline \multirow{2}{*}{ Region } & $\mathbf{2 0 0 9}$ & $\mathbf{2 0 1 0}$ & $\mathbf{2 0 1 1}$ & $\mathbf{2 0 1 2}$ \\
\cline { 2 - 5 } & $\mathbf{( \% )}$ & $\mathbf{( \% )}$ & $\mathbf{( \% )}$ & $\mathbf{( \% )}$ \\
\hline Indonesia & 65.0 & 67.5 & 71.2 & 75.9 \\
Jawa-Bali & 69.8 & 71.4 & 72.3 & 77.9 \\
Sumatra & 60.9 & 67.1 & 69.4 & 77.4 \\
Kalimantan & 55.1 & 62.3 & 64.3 & 76.7 \\
Sulawesi & 54.4 & 62.7 & 66.6 & 67.5 \\
Eastern Indonesia & 31.8 & 35.7 & 44.2 & 54.0 \\
\hline
\end{tabular}

Electrical energy is very important in the civilization development, and it always increases every year. The demand for electrical energy went up in the last periods in many countries, including Indonesia. It grew up as the impact of the higher number of population and economic growth [5],[6],[7],[8]. As an impact, the number of electrical energy user increased from 7.1 million in 2009 to 9.2 million in 2012. In other words, the users grew $28.8 \%$ during that period. The electrical energy consumption was also rose up $36.6 \%$ from 16.827 GWh in 2009 to $22.993 \mathrm{GWh}$ in 2012. Furthermore, that situation affects the generating capacity in the Sumatra system, which it had not been able to meet the demand. The power generation capacity of Sumatra system is presented in Table 3, while Table 4 presents the expansion plan.

Table 3. Generating capacity of Sumatra system in 2010

\begin{tabular}{ccc}
\hline Type & Capacity (MW) & Max Availability (MW) \\
\hline PLTA & 982,6 & 978 \\
PLTD & 519,9 & 489,7 \\
\hline
\end{tabular}



Vol. 5, No. 1, Juni 2019, pp. 16-25

\begin{tabular}{crc}
\hline PLTG & 842 & 786,5 \\
PLTG & 210 & 195 \\
PLTGU & 859 & 773 \\
PLTMG & 73,8 & 73,8 \\
PLTMH & 23,6 & 22,4 \\
PLTP & 11 & 10 \\
PLTU & 915 & 895 \\
PLTU & 260 & 195 \\
\hline Total & 4696,9 & 4418,4 \\
\hline
\end{tabular}

Table 4. Generating capacity expansion plan based on FTP 1 and FTP 2

\begin{tabular}{lc} 
Jenis Pembangkit & Kapasitas Total (MW) \\
\hline PLTA & 558 \\
PLTU & 1746 \\
PLTG & 564 \\
PLTD & 384 \\
PLTP & 2824 \\
PLTBM & 30 \\
\hline \multicolumn{2}{r}{ Total } \\
\hline
\end{tabular}

\section{RESEARCH METHOD}

\subsection{Integrated resource planning approach}

This research used integrated resource planning (IRP) as an approach to the analysis, which is built in the LEAP software. The IRP approach is implemented to make a comprehensive analysis of the Sumatra electricity system. The analysis includes multiple aspects of electricity planning such as technical, economic and environment. Otherwise, through the IRP approach, the analysis could be possible to involve three important sectors of the reference energy system, are the supply, the transmission and distribution and the demand.

The Sumatra system will be modelled based on the IRP framework using LEAP software. LEAP has four main modules which are represented parts of the reference energy system. The modules consist of a demand module, a transformation module, and a resource module. For supporting the comprehensive analysis, LEAP also provides analysis related to the environmental aspect, optimization analysis and cost-benefit analysis.

IRP is a combination of electricity expansion planning analysis in the supply side and the increase of energy efficiency including the demand-side management (DSM) option in the demand side, intending to provide electricity services with minimum cost, including the socio-environment cost [9]. IRP is very useful in both energy demand projection and the projection of annual peak requirement through a combination of SSM and DSM in a certain period in the future [10]. There are five key elements in IRP: 1) Definition and explicit statement of objectives; 2) Energy and demand forecasting; 3) Assessment and planning of demand options; 4) Assessment and planning of supply options; 5) Integrated planning (selection of options). Nowadays, there are some integrated analytical models which have similarities to the IRP model known as integrated energy resources planning [11],[12],[13].

\subsection{Modelling tool}

LEAP (Long-range Energy Alternative Planning) is a popular tool in energy modelling and has been used in many countries [14],[15],[16]. With accounting basis, LEAP framework is very flexible for many types of models, competencies, areas and methodologies [17],[18],[19],[20]. Many types of research had been carried out using this tool, such as energy demand analysis, greenhouse gas emission analysis, and sustainable energy transition analysis [21],[22]. The main benefit of this tool is its low initial data requirements.

This study is started by literature study continued with data collection and data compilation. Next, the IRP framework is built using LEAP software based on the collected data. The next steps are projecting the electricity demand, DSM option investigation, SSM option investigation, IRP analysis, and finished with preparing the conclusion and recommendations. The complete steps of this study are shown in Fig.1. 


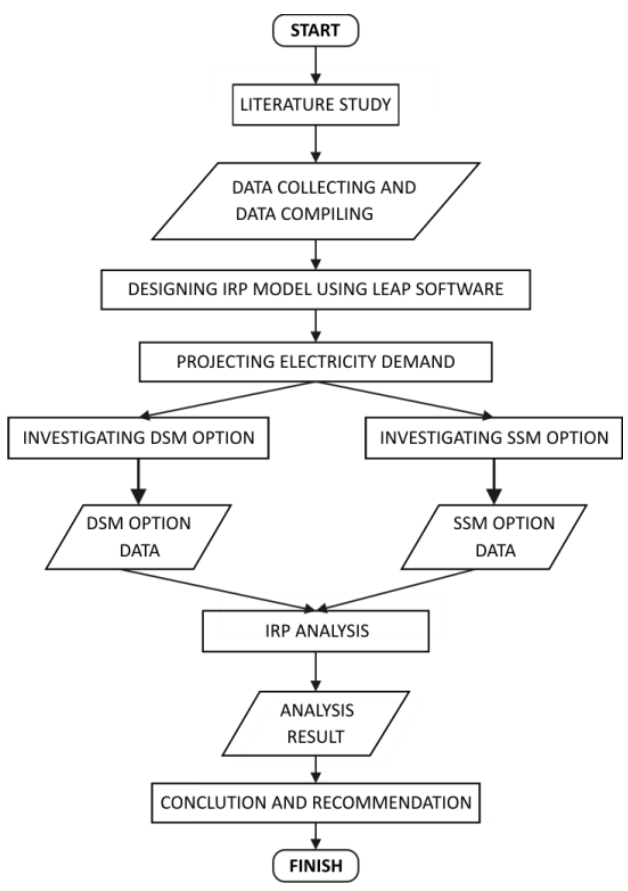

Fig. 1. Flowchart of the study

\subsection{Final electrical energy demand analysis and forecasting method}

Final electrical energy demand (FEED) is calculated for each year and branch (sector) and determined as a product of activity times electrical energy intensity shown in (1).

$$
F E E D_{b, s, t}=A_{b, s, t} \cdot E E I_{b, s, t}
$$

FEED is final electrical energy demand, and $A$ is an activity which is, in this case, will substitute the number of customers or users, $E E I$ is electrical energy intensity, $b$ is a branch (sector of the customer), $s$ is scenario and $t$ is time (year). In advance, the forecasting method that is used in this model is not complicated. The forecasting methods in this model are shown in (2) until (6). The number of household sector customers at each year was represented as the result of the number of population $(P)$ divided by household size $(H S)$ then multiple by electrification ratio $(E R)$. As a result, the $F E E D$ will be calculated using (3). In three other group of customers such as industrial $(i)$, commercial $(c)$, and public $(p)$, the FEED will be calculated as the result of total customer $(T C)$ times electricity intensity $(E I)$.

$$
\begin{aligned}
& T C_{h, s, t}=\frac{P_{s, t}}{H S_{s, t}} \cdot E R_{s, t} \\
& F E E D_{h, s, t}=\frac{P_{s, t}}{H S_{s, t}} \cdot E R_{s, t} \cdot E I_{h, s, t} \\
& F E E D_{i, s, t}=T C_{i, s, t} \cdot E I_{i, s, t} \\
& F E E D_{c, s, t}=T C_{c, s, t} \cdot E I_{c, s, t} \\
& F E E D_{p, s, t}=T C_{p, s, t} \cdot E I_{p, s, t}
\end{aligned}
$$

\subsection{Calculation of supply}

Power generation capacity under the LEAP model was calculated using the endogenous method to maintain the specified planning reserve margin (PRM). As a first step, the existing capacity is calculated using (7).

$$
C_{B A}=\left(C_{E X}+C_{E N}\right) \times C_{\text {value }}
$$

where:

$\mathrm{C}_{\mathrm{BA}} \quad$ : capacity before addition (MW)

$\mathrm{C}_{\mathrm{EX}} \quad$ : exogenous capacity (MW)

$\mathrm{C}_{\mathrm{EN}} \quad$ : endogenous capacity added previously (MW)

$\mathrm{C}_{\text {value }} \quad$ : capacity value (MW)

Peak system power requirements on the module are calculated by the following (8), 


$$
C_{\text {peak }}=\frac{E}{L F \times 8760[\text { hours/ year }]}
$$

where

$\mathrm{C}_{\text {peak }} \quad$ : Peak Requirement (MW),

E : Energy Requirement (MWh),

LF : Module Load Factor.

PRM The reserve margin before the addition of endogenously calculated additions is calculated as (9), with $\mathrm{PRM}_{\mathrm{BA}}$ is reserve margin before additions.

$$
P R M_{B A}=\left(C_{B A}-C_{\text {peak }}\right) / C_{\text {peak }}
$$

Then, the amount of endogenous capacity additions required is calculated as (10),

$$
C_{E N A}=\left(P R M-P R M_{B A}\right) \times C_{\text {peak }}
$$

$\mathrm{C}_{\mathrm{ENA}}$ is Endogenous Capacity Additions Required which is needed to maintain the specified reserve margin. LEAP will calculate the generation capacity required for each electricity generation process.

In the optimization scenario, the power generation is dispatched based on the running cost. The load duration curve (LDC) data is required to activate the process. Based on the LDC data, LEAP will calculate and simulate the dispatching process in each type of power plant to meet the electricity demand. The running cost is calculated by (11).

$$
\text { Running Cost }_{i}=\text { VariableOMCost }_{i}+\frac{\text { FuelCost }_{i}}{\text { Efficiency }_{i}}
$$

To do a simulation with the dispatch process, LEAP will sort all the power plant processes first based on merit orders. Information from this sorting process is used to calculate the capacity available for each group of merit orders. Thus LEAP simultaneously dispatches each group with the same merit order. Furthermore, LEAP takes a discrete approach to LDC that has been determined and divided into time slice intervals.

\subsection{Scenario}

\section{Demand scenario}

Demand scenario is the projection of electricity demand using two different assumptions. First demand scenario is named as business as usual (BAU) while the other one is named as energy conservation scenario (EC). Under scenario BAU, the demand projection is calculated based on the existing condition without any intervention in policy and other assumption. In the scenario EC, there are energy conservation programs which are implemented in the household sector, commercial sector and public sector. The energy conservation action is expected to make an impact in reducing the annual electricity intensity.

\section{Supply scenario}

Supply scenario is a group of scenarios that projected the condition of electricity supply in the Sumatra system. This scenario group consisting of nine scenarios, the BAU scenario, EC, natural gas, geothermal, coal, alternative, bio-energy, mandatory biofuel and biofuel substitution. BAU scenario and EC scenario are integrated into the demand scenario. However, on this site is seen from the aspect of the supply. In the seven other scenarios, each used a different kind of fuel of power plant. In the alternative scenario, the power generation system uses a combination of power plants fueled by natural gas, coal, geothermal, biomass and biofuels. Meanwhile, mandatory biofuel scenarios reflect the implementation of mandatory biofuel policy on the electrical system of Sumatra where the use of biodiesel fuel is targeted to be replaced by a certain amount of biodiesel and pure palm oil.

\section{Optimization scenario}

Scenario optimization is a simulation to obtain the optimal combination of power plants in terms of costs and environmental impact. This scenario is divided into three, namely the optimization scenario, emissions 26 scenarios and emission 41 scenarios. The optimization scenario is simulated without putting restraints representing any policy. This optimization was conducted using the lowest possible running costs. On the other side, emissions 26 scenario is a plant optimization with restraints limit emissions reduction by $26 \%$ of emissions in the BAU scenario. Meanwhile, emission 41 scenarios using restraints reduce emissions by $41 \%$. This optimization scenario using different types of power plant.

\section{Integrated scenario}

This scenario is a combination of energy conservation (EC) scenario with the supply scenario and the optimization scenario. As explained, that one IRP analysis process is to combine the SSM option with DSM option. 


\section{RESULTS AND DISCUSSION}

\subsection{Electricity demand projections in sumatra interconnection system}

The projection of electricity demand in Sumatra interconnection system shown in Table V. The BAU scenario indicates that the electrical energy demand in Sumatra will increase more than $700 \%$ from the base year. Electricity demand in the household sector will increase from 10790 Giga Watthours in 2010 to 76596 Giga Watthours in 2035. The industrial demand in the early period was 3682 Giga Watthours and became 21920 Giga Watthours at the end of the period. The electricity demand for the commercial sector will increase from 31484 Giga Watthours to 3558 Giga Watthours. Meanwhile, electricity demand for public sector increased to $15277 \mathrm{GWh}$ in 2035 from the original $1732 \mathrm{Giga}$ Watthours in 2010. Table 5 shows the forecasting results according to the BAU scenario.

Table 5. Electrical energy demand in Sumatra 2010-2035 according to the BAU scenario

\begin{tabular}{lrrrrrr}
\hline \multirow{2}{*}{ Sector } & \multicolumn{5}{c}{ Electricity demand $(\mathbf{G W h})$ according to the BAU scenario } \\
\cline { 2 - 7 } & $\mathbf{2 0 1 0}$ & $\mathbf{2 0 1 5}$ & $\mathbf{2 0 2 0}$ & $\mathbf{2 0 2 5}$ & $\mathbf{2 0 3 0}$ & $\mathbf{2 0 3 5}$ \\
\hline Household & 10790 & 18785 & 31067 & 42450 & 57292 & 76596 \\
Industry & 3682 & 5260 & 7515 & 10738 & 15342 & 21920 \\
Commercial & 3558 & 5502 & 8510 & 13162 & 20357 & 31484 \\
Public & 1732 & 2677 & 4138 & 6395 & 9884 & 15277 \\
Total & 19761 & 32225 & 51231 & 72745 & 102875 & 145277 \\
\hline
\end{tabular}

The projection of electricity demand in Sumatra interconnection system is also carried out based on energy conservation (EC) scenario. The EC scenario is a combination of the application of DSM programs in the household sector, the business sector and the public sector. The projection of electricity demand, according to EC scenario shown in Table 6. Electricity demand in the household sector in 2035 became 75222 GWh. Electricity demand in the commercial sector became $30148 \mathrm{GWh}$ in the year 2035. Meanwhile, electricity demand for public sector became $14676 \mathrm{GWh}$ in 2035. Total demand for electricity in 2035 was 141965 GWh.

Table 6. Electrical energy demand in Sumatra 2010-2035 according to EC scenario

\begin{tabular}{lrrrrrr}
\hline \multirow{2}{*}{ Sektor } & \multicolumn{5}{c}{ Electricity demand $(\mathbf{G W h})$ according to EC scenario } \\
\cline { 2 - 7 } & $\mathbf{2 0 1 0}$ & $\mathbf{2 0 1 5}$ & $\mathbf{2 0 2 0}$ & $\mathbf{2 0 2 5}$ & $\mathbf{2 0 3 0}$ & $\mathbf{2 0 3 5}$ \\
\hline Household & 10790 & 18785 & 29866 & 41180 & 55964 & 75222 \\
Industry & 3682 & 5260 & 7515 & 10738 & 15342 & 21920 \\
Commercial & 3558 & 5502 & 8128 & 12582 & 19476 & 30148 \\
Public & 1732 & 2677 & 3941 & 6110 & 9470 & 14676 \\
Total & 19761 & 32225 & 49450 & 70609 & 100252 & 141965 \\
\hline
\end{tabular}

Based on the results, electricity demand in the EC scenario is lower than the electricity demand in the BAU scenario. By implementing DSM programs in the three customer sectors, EC scenario able to reduce the electricity demand by $3.98 \%$ in 2016 and $2.28 \%$ in 2035 . In 2020, electricity demand fell by $3.47 \%$. Meanwhile, respectively in 2025 and 2030, the EC scenarios able to reduce the electricity demand by $2.94 \%$ and $2.55 \%$. The percentage of savings tend to become smaller from year to year. These suggest that the growth of the electric energy intensity is a much greater influence than the savings made.

\subsection{Transmission and distribution}

Electricity generated by the power plant to be distributed to consumers through a system of conductors. The conductor system is often referred to as transmission and distribution systems. Transmission and distribution system in Sumatra had a value lost of 9.7\%. Value losses are assumed to be fixed during the simulation period by the BAU scenario. The amount of energy loss during the period 2010-2035 are shown in Table 7.

Table 7. Electricity losses in transmission and distribution system 


\begin{tabular}{lllllll}
\hline \multirow{2}{*}{ Scenario } & \multicolumn{7}{c}{ Losses $(\mathbf{G W h})$} \\
\cline { 2 - 7 } & $\mathbf{2 0 1 0}$ & $\mathbf{2 0 1 5}$ & $\mathbf{2 0 2 0}$ & $\mathbf{2 0 2 5}$ & $\mathbf{2 0 3 0}$ & $\mathbf{2 0 3 5}$ \\
\hline BAU & 2123 & 3462 & 5503 & 7814 & 11051 & 15606 \\
EC & 2123 & 3462 & 5312 & 7585 & 10769 & 15250 \\
\hline
\end{tabular}

\subsection{Supply of electricity on sumatra interconnection system}

To analyze the supply of electricity in the Sumatra interconnection system, using a scenario approach to analysis. There are various scenarios to simulate the supply of the system. The scenarios were used to estimate the impact of the policies that have been planned by the government to the Sumatra system.

In the BAU scenario, the expansions of the electricity generation plan were simulated based on the fast track program (FTP) phase 1 and phase 2. The simulation results show an increase in generating capacity. In 2015, the electricity generation capacity became 6612 MW. In 2020, it still moves up, and it becomes 9300 MW while in 2022 the electricity generation capacity becomes $10805 \mathrm{MW}$. This scenario observed from the energy balance perspective, show that the government policy through FTP 1 and FTP 2 will not be able to meet the energy demand from 2015 to 2035. In 2015, the electricity deficit in Sumatra system was $36 \mathrm{GWh}$. It is a small value. However, a significant deficit will start in 2020 . The electricity deficit will become $2000 \mathrm{GWh}$ in 2020 and still increase until $96000 \mathrm{GWh}$ in 2035.

One of the solutions prepared for resolving the electricity deficit is the implementation of demand-side management (DSM) program. The simulation results based on the DSM scenario show that this DSM program will be able to delay the electricity deficit. In the BAU scenario, the electricity deficit starts in 2015 while in the DSM scenario, the deficit will start in 2018. In 2018, the Sumatra system will have about $1 \mathrm{GWh}$ electricity deficit while in 2035 the deficit becomes $93000 \mathrm{GWh}$. There is a difference of $3000 \mathrm{GWh}$ compared to the BAU scenario.

The next government policy simulated in this study is the biofuel mandatory. The BM scenario simulated of the policy. The simulation results show there are no differences in generation capacity, electricity production and energy balance. However, there are some differences found in the energy mix and the environmental impact when it compared to the BAU scenario. Simulation with BAU scenario resulting in emissions as much as 28 million tons of carbon dioxide equivalent (CDE) from the electricity generation process at the end of the simulation year. That emissions can be reduced by 2 million tons CDE through the BM scenario. The BM scenario, resulting in emissions as much as 26 million tons CDE in 2035.

Though either DSM scenario and BM scenario have an impact in delaying electricity deficit and in reducing carbon emissions, the deficit will still happen after 2022. An alternative scenario was presented to full fill the demand from the simulation results known that the alternative scenario will eliminate the deficit in Sumatra system. Through the alternative scenario, the power plant capacity can be expanded, and it will affect electricity production to be greater.

\subsection{Power plant optimization}

Power Plant Optimization aims to obtain the optimal combination of various types of power plant. There are three scenarios with each scenario have a different option. One scenario is called an optimization scenario. This scenario has no constrained related to neither cost nor emission. Two other scenarios have a constraint related to the emissions. The simulation results show that scenarios with emission constraint give different options than the optimization scenario. Both the emission 26 scenario and the emission 41 scenario use clean energy options more than the optimization scenario. In 2035, the emission 26 scenario causes 20,7 million tons CDE while the emission 41 send 16,5 million tons CDE to the atmosphere. To be compared, the optimization scenario causes 56,1 million tons of CDE in 2035. Even though the optimization scenario caused more emissions, it had an advantage seen from the cost perspective. The production cost in the optimization scenario is the cheapest among the scenarios.

\subsection{IRP analysis}

A comparative analysis of the scenarios is presented based on two aspects, namely is environmental analysis and cost analysis. The analysis is aimed to identify the cleanest option/scenario and the cheapest one with considering the fulfilment of the electricity demand.

From all the options scenarios on the supply side, the use of coal and natural gas will produce the highest emissions. Coal scenario is estimated to emit as much as 1300 million tons of $\mathrm{CO} 2$ equivalent, while the natural gas scenario produces emissions by 1021 million tons of $\mathrm{CO} 2$ equivalent. Alternative scenario plant is estimated to produce emissions of 862 million tons of $\mathrm{CO} 2$ equivalent. The calculation in the optimization 
scenarios show emissions produced by 750 million tons of $\mathrm{CO} 2$ equivalent while the lowest emissions were produced by the emissions 41 scenarios in the number of 385 million tons of $\mathrm{CO} 2$ equivalent.

From the simulation results can be seen that for developing the generation system with priority utilization of geothermal energy is needed costs 6531 trillion rupiahs. This value is the highest among other options. However, if it viewed through the environmental aspects, the geothermal option should be considered because its emissions are even lower than the optimization scenario. When viewed from the total costs, the optimization scenario requires a total capital cost amounted to IDR 291 trillion. Operating costs consists of fixed O \& M amounted to IDR 112 trillion and variable $\mathrm{O} \& \mathrm{M}$ for IDR 63 trillion. Each of these values is smaller when compared with the cost of the scenario Emissions 26 and the scenario Emissions 41. The emissions generated by each scenario is shown in Fig. 2.

Integration of energy conservation scenarios into groups of optimization scenarios is also capable of lowering capital costs, fixed $\mathrm{O} \& \mathrm{M}$ costs, and variable $\mathrm{O} \& \mathrm{M}$ costs. After integration, capital costs, fixed $\mathrm{O}$ \& $\mathrm{M}$ costs, and variable $\mathrm{O} \& \mathrm{M}$ costs at each optimization scenario became IDR 287.5 trillion, IDR 110.7 trillion and IDR 60.6 trillion. IRP analysis results showing the comparative cost of the entire scenario is shown in Fig. 3.

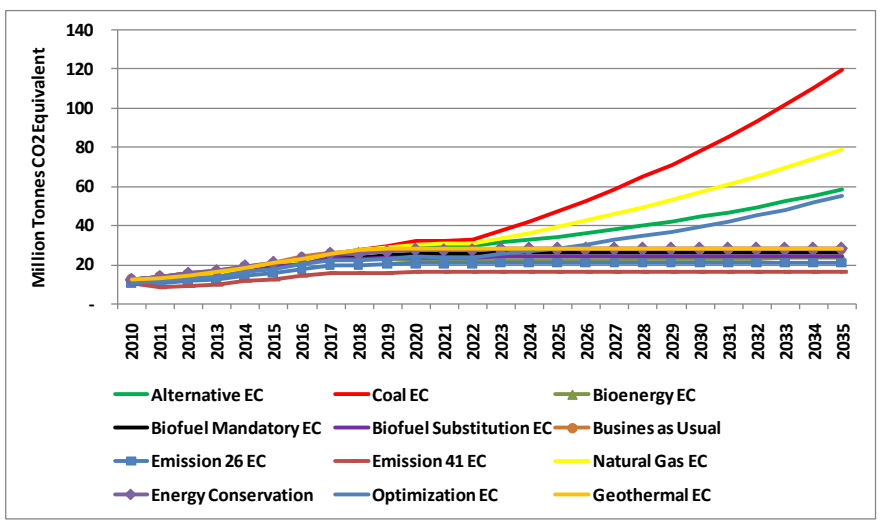

Fig. 2. Comparation of the emissions generated in each scenario

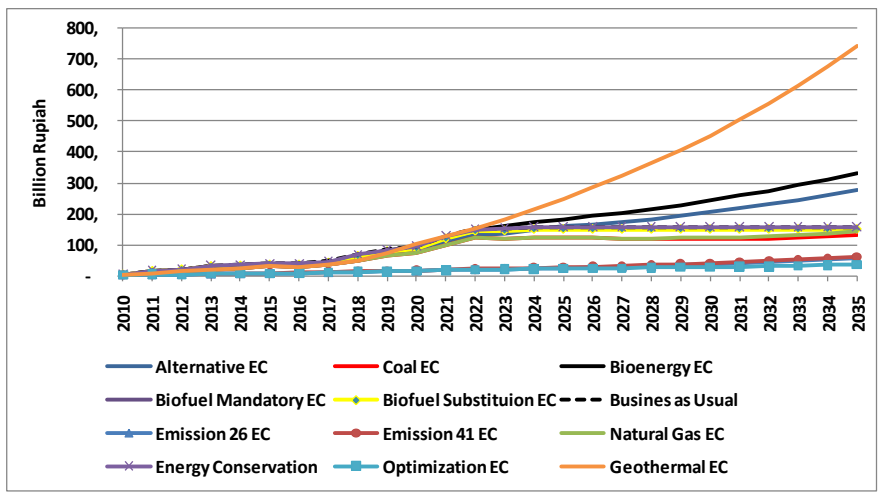

Fig. 3. Comparison of cost for each scenario

\section{CONCLUSION}

Based on the results of the simulation and analysis of demand and analysis of the supply of electricity in Sumatra interconnection system using 12 integrated scenarios that can be divided into four parts. First, the demand for electricity on the Sumatra interconnection system will be increased by an average of $8.32 \%$ per year over the period 2010-2035. Demand for electricity in the household sector grew at an average of $8.18 \%$ per year. Demand for electrical energy in the industrial sector grew an average of $7.4 \%$, the business sector grew an average of $9.11 \%$, and the public sector grew an average of $9.10 \%$ per year. Application of DSM programs on Energy Conservation scenario will reduce the electricity demand growth to $8.22 \%$ per year.

Second, implementation of plant development through an FTP program (phase 1 and phase 2) has not been able to meet the entire demand for electricity, especially after 2022. To overcome several alternative solutions proposed as scenarios. Energy conservation scenario will be able to defer the deficit until 2017, while the alternative scenario would eliminate the deficit of the fastest start in 2021. Third, implementation of mandatory biofuel policy would reduce the level of emissions from power plants in Sumatra interconnection system amounted to $6.33 \%$ compared with no such policy. 
Fourth, to meet the electricity needs until the year 2035, the best option is the lowest-cost aspect of optimization scenarios. Optimization scenario is developing power plants with diverse types. From the environmental aspect, scenario Emissions 41 is the best option to have the lowest emission levels. Emissions Scenario 41 is a picture of the implementation of policies contained in RAN-GRK targeting emissions reductions at power plants by $41 \%$.

IRP analysis has been carried out and produce the best option based on two aspects that were examined, the environmental aspects and the cost aspects. According to the cost aspect, integration of the optimization scenario and the energy conservation policy is an option with the lowest cost is IDR 458.7 trillion. According to the environmental aspects, the integration policy of energy conservation and emission 41 scenarios is an option with the lowest emissions impact that is 385 million tonnes of $\mathrm{CO} 2$ equivalent.

\section{REFERENCES}

[1] H. Syadli, M. P. Abdullah, M. Y. Hassan, and F. Hussin, "Demand side management for reducing rolling blackouts due to power supply deficit in sumatra," J. Teknol. Sciences Eng., vol. 69, no. 5, pp. 39-43, 2014, doi: 10.11113/jt.v69.3202.

[2] Y. Putrasari, A. Praptijanto, W. B. Santoso, and O. Lim, "Resources, policy, and research activities of biofuel in Indonesia: A review,” Energy Reports, vol. 2, pp. 237-245, 2016, doi: 10.1016/j.egyr.2016.08.005

[3] L. Gacitua et al., "A comprehensive review on expansion planning: Models and tools for energy policy analysis," Renew. Sustain. Resources, policy, and research activities of biofuel in Indonesia: A review Energy Rev., vol. 98, no. September, pp. 346-360, 2018, doi: 10.1016/j.rser.2018.08.043.

[4] A. Mirakyan and R. De Guio, "Modelling and uncertainties in integrated energy planning," Renew. Sustain. Energy Rev., vol. 46, no. 0, pp. 62-69, 2015, doi: 10.1016/j.rser.2015.02.028.

[5] Y. Tanoto, E. A. Handoyo, and R. Sutjiadi, "Accounting framework based electricity energy planning software involving renewable energy," ICCEREC 2015 - Int. Conf. Control. Electron. Renew. Energy Commun., pp. 103-107, 2015, doi: 10.1109/ICCEREC.2015.7337025.

[6] H. Mubarok and R. Septyawan, "Analysis of PLN's Electrical Energy Demand in the Area of Batam-Indonesia Using the Linear Regression Method," Proc. - 2018 4th Int. Conf. Sci. Technol. ICST 2018, vol. 1, pp. 1-5, 2018, doi: 10.1109/ICSTC.2018.8528660.

[7] Y. Lefaan and R. Dalimi, "Electricity Demand Forecasting of Household Sector in Papua Province 2050," Proc. 2018 Int. Conf. Electr. Eng. Comput. Sci. ICECOS 2018, vol. 17, pp. 291-296, 2019, doi: 10.1109/ICECOS.2018.8605233.

[8] M. A. McNeil, N. Karali, and V. Letschert, "Forecasting Indonesia's electricity load through 2030 and peak demand reductions from appliance and lighting efficiency," Energy Sustain. Dev., vol. 49, pp. 65-77, 2019, doi: 10.1016/j.esd.2019.01.001.

[9] C. A. Dortolina, N. Bacalao, R. Nadira, and P. De Arizon, "Integrated resource planning in developing countries - a novel practical approach," in IEEE Power Engineering Society General Meeting, 2004, vol.2, pp. 1243-1249, 2004, doi: 10.1109/PES.2004.1373054.

[10] R. Wilson and B. Biewald, Best Practices in Electric Utility Integrated Resource Planning. Montpeiler: Synapse Energy Economics, 2013, available at: Google Scholar.

[11] O. T. Kinto, J. L. De Oliveira Bernal, A. L. Veiga Gimenes, and M. E. Morales Udaeta, "Sustainable Energy Technologies in the Industry Using Integrated Energy Resources Planning,” Energy Procedia, vol. 118, pp. 4-14, 2017, doi: 10.1016/j.egypro.2017.07.002.

[12] M. M. Rafique and G. Ahmad, "Targeting sustainable development in Pakistan through planning of integrated energy resources for electricity generation," Electr. J., vol. 31, no. 7, pp. 14-19, 2018, doi: 10.1016/j.tej.2018.08.001.

[13] Y. Zheng, D. Ren, Z. Guo, Z. Hu, and Q. Wen, "Research on integrated resource strategic planning based on complex uncertainty simulation with case study of China," Energy, vol. 180, pp. 772-786, 2019, doi: 10.1016/j.energy.2019.05.120.

[14] N. Indrawan et al., "Palm biodiesel prospect in the Indonesian power sector," Environ. Technol. Innov., vol. 7, pp. 110-127, 2017, doi: 10.1016/j.eti.2017.01.001.

[15] R. D. Prasad and A. Raturi, "Low carbon alternatives and their implications for Fiji's electricity sector," Util. Policy, vol. 56, no. February 2018, pp. 1-19, 2019, doi: 10.1016/j.jup.2018.10.007.

[16] A. Bhuvanesh, S. T. Jaya Christa, S. Kannan, and M. Karuppasamy Pandiyan, "Aiming towards pollution free future by high penetration of renewable energy sources in electricity generation expansion planning," Futures, vol. 104, no. December 2017, pp. 25-36, 2018, doi: 10.1016/j.futures.2018.07.002.

[17] N. H. Mirjat, M. A. Uqaili, K. Harijan, G. Das Walasai, M. A. H. Mondal, and H. Sahin, "Long-term electricity demand forecast and supply side scenarios for Pakistan (2015-2050): A LEAP model application for policy analysis," Energy, vol. 165, pp. 512-526, 2018, doi: 10.1016/j.energy.2018.10.012.

[18] G. Hu, X. Ma, and J. Ji, "Scenarios and policies for sustainable urban energy development based on LEAP model A case study of a postindustrial city: Shenzhen China," Appl. Energy, vol. 238, no. May 2018, pp. 876-886, 2019, doi: 10.1016/j.apenergy.2019.01.162.

[19] C. Liya and G. Jianfeng, "Scenario analysis of CO 2 emission abatement effect based on LEAP," Energy Procedia, vol. 152, pp. 965-970, 2018, doi: 10.1016/j.egypro.2018.09.101.

[20] N. V. Emodi, T. Chaiechi, and A. B. M. R. Alam Beg, "Are emission reduction policies effective under climate change conditions? A backcasting and exploratory scenario approach using the LEAP-OSeMOSYS Model," Appl. 
Energy, vol. 236, no. December 2018, pp. 1183-1217, 2019, doi: 10.1016/j.apenergy.2018.12.045.

[21] J. A. Nieves, A. J. Aristizábal, I. Dyner, O. Báez, and D. H. Ospina, "Energy demand and greenhouse gas emissions analysis in Colombia: A LEAP model application," Energy, vol. 169, pp. 380-397, 2019, doi: 10.1016/j.energy.2018.12.051.

[22] J. H. Hong et al., "Long-term energy strategy scenarios for South Korea: Transition to a sustainable energy system," Energy Policy, vol. 127, no. July 2018, pp. 425-437, 2019, doi: 10.1016/j.enpol.2018.11.055. 